\title{
Estratégia de Zoneamento Ambiental Aplicada a Caracterização Ambiental de Bacias Hidrográficas do Semiárido Brasileiro: Estudo de Caso na Microbacia do Rio Barra Nova - RN/PB.
}

\author{
Applied Environmental Zoning the Watershed Environmental Characterization of the \\ Brazilian Semiarid Strategy: A Case Study on Watershed Rio Barra Nova - RN / PB.
}

GUEDES $^{1}$, J. C. F.; $\operatorname{MEDEIROS}^{1}$, A.D.; $\operatorname{COSTA}^{2}$, D. F. S.

email:janiocf.guedes@gmail.com

\begin{abstract}
Resumo
Estudos relativos ao planejamento têm uma série de denominações, como planejamento ambiental, estratégico, participativo ou regional. Todavia, qualquer que seja a adjetivação, o planejamento deve tomar decisões, requerendo estudos integrados nos quais selecionem e sistematizem informações sobre a área ou local onde ele será aplicado. O presente trabalho teve como objetivo realizar o zoneamento e a delimitação de áreas prioritárias para a conservação e/ou recuperação ambiental na Microbacia Hidrográfica do Rio Barra Nova (RN/PB). Foram utilizadas técnicas de geoprocessamento para a geração de mapas temáticos de uso e ocupação do solo (Caatinga densa, Caatinga rala e Solo exposto) em escala de 1: 400.000, onde a Caatinga densa representa uma área de $30,42 \%$, a Caatinga rala de $37,25 \%$ o solo exposto representa $31,28 \%$ e a drenagem hidrográfica representa uma área de 1,05\%. Após definidas essas classes, foi elaborado um mapa de zoneamento (zona de uso restrito, zona de risco e zona de recuperação), a partir do qual cada zona foi analisada e segmentada considerando-se a prioridade na realização de ações de intervenção voltadas para a conservação/recuperação ambiental.
\end{abstract}

Palavras-chave: SIG, Planejamento Ambiental, Microbacia do Rio Barra Nova - RN/PB.

\begin{abstract}
Planning-related studies have a number of names, such as environmental, strategic, participatory planning and regional. However, regardless of the aforementioned, the planning should make decisions, requiring integrated studies which select and systematize information on the area or place where they are applied. The present work aimed to perform zoning and demarcation of priority areas for conservation and/or environmental recovery in Barra Nova River Watershed (RN/PB). GIS techniques were used to generate thematic maps of soil use and occupation (dense Caatinga, thin Caatinga and Exposed soil) on a scale of 1: 400,000, where the dense Caatinga represents an area of $30.42 \%$, the thin Caatinga, $37.25 \%$, the Exposed soil, $31.28 \%$ and drainage basin represents an area of 1, 05\%. After defined these classes, it was designed a zoning map (restricted use zone, danger zone and recovery area) from which each zone was analyzed and segmented by considering the priority in conducting intervention activities in aimed at conservation/environmental recovery.
\end{abstract}

Keywords: GIS, environmental planning, Barra Nova River Watershed-RN/PB. 


\section{INTRODUÇÃO}

Pesquisas relacionadas ao planejamento têm uma série de denominações, como planejamento ambiental, estratégico, participativo ou regional. Todavia, qualquer que seja a adjetivação, o planejamento deve está ligado a tomada de decisões, para isso tal atividade requer estudos integrados nos quais selecionem e sistematizem informações sobre a área ou local onde ele será aplicado e identifique o estado do ambiente, a pressão exercida sobre ele e a resposta dada pela sociedade para sua melhoria (VILA-SILVA, 2003), considerando que os sistemas ambientais (geossistemas) são integrados por variados elementos que mantêm relações mútuas entre si e são continuamente submetidos aos fluxos de matéria e de energia (BERTRAND, 1969).

No atual cenário dos estudos ambientais, as bacias hidrográficas estão em foco, pois estas tem um funcionamento sistêmico, que facilita análise dinâmica do conjunto de elementos e unidades que compõe o sistema e também permite indagar e averiguar as relações entre estes e o meio que está inserido (CRISTOFOLLETI, 1999). Nesse sentido, o uso do conceito de Bacia Hidrográfica em projetos de planejamento ambiental tem sido bastante defendido, em função de a bacia ser considerada como a unidade mais adequada para o estudo da estrutura e da dinâmica do meio ambiente, especialmente quando se busca uma análise regional (ROCHA et al., 2000; SCHIAVETTI.; CAMARGO, 2002).

Desse modo, é importante ressaltar a necessidade do desenvolvimento concomitante a ações que conservem a natureza tendo como foco buscar estratégias capazes de levantar, ponderar e integrar dados dos componentes dos ecossistemas. Uma destas estratégias é o zoneamento, uma ferramenta fundamental que serve de base para o planejamento ambiental, e que auxilia a definir no ambiente ou zonas homogêneas em função de suas variáveis ambientais.

Para Spörl (2001), além do zoneamento, outra importante estratégia é o mapeamento da fragilidade ambiental, a partir da qual são identificados e analisados os ambientes em função de sua fragilidade. Pode-se assim, apontar áreas com graus de fragilidade menor, as quais favorecem determinados tipos de inserção, e também áreas com maior fragilidade, nas quais são exigidas ações tecnicamente mais adequadas a essas condições.

Para tal, é necessário desenvolver propostas metodológicas que efetivem medidas reais e quantitativas relacionadas ao meio ambiente, que simplifiquem a expressão dos resultados obtidos e que sejam de fácil acesso e repetição pelas pessoas envolvidas nesta área do conhecimento (VILASILVA, 2003). Dentro da visão de proteção ambiental, os Sistemas de Informações Geográficas (SIGs) são criados para servirem de base para as tomadas de decisão, ou seja, para obter informações e utilizá-las com fins de gerar respostas que satisfaçam às necessidades do 
planejamento ambiental, fazendo-se necessária à existência de uma base cartográfica e um sistema de informações estruturado (NICÁCIO e LOCH, 2002).

Segundo Câmara et al., (2004), um SIG tem como objetivo adquirir, armazenar, recuperar e transformar dados espaciais. Estes sistemas computacionais vêm se tornando cada vez mais comuns, devido à disponibilidade por um baixo custo e com interfaces amigáveis, onde os setores governamentais e privados têm adotado esses métodos para análises precisas, estudos e levantamentos de dados.

Diversos autores vêm ressaltando a importância do uso de SIG como ferramentas em importantes trabalhos científicos em bacias hidrográficas sobre análises de sistemas (e.g. OSTENSEN, 1995; CÂMARA et al., 1996; CÂMARA e MEDEIROS, 1996), diagnóstico do meio físico (e.g. SILVA et al., 1999; CARVALHO JUNIOR et al., 2003; DUARTE, 2003; FARIA FILHO e ARAÚJO, 2003; LACERDA, 2003; LIMA, 2003; PEDRA et al., 2005; PINTO et al., 2005; ROCHA, 2005), modelagem (e.g. MOLENAAR, 1996; CRISTOFOLLETI, 1999) e avaliação de impactos ambientais (e.g. ALVES et al., 2000; SCHÄFER et al., 2004; TRANCOSO et al., 2005), colocando sempre sua importância na integração e visualização de dados, gerência de novas informações como um sistema de suporte para a tomada de decisão.

No Brasil, a exploração dos recursos naturais, principalmente na zona semiárida, tida como ambiente ecologicamente instável e de forte ação antrópica (AB'SABER, 1977), faz com que esta região seja considerada bastante susceptível ao desencadeamento do processo de desertificação. O atual conceito de Desertificação, como definido pela Convenção das Nações Unidas de Combate a Desertificação - UNCCD, diz que se trata de um processo de degradação de terras que ocorre em regiões de clima árido, semiárido ou subúmido seco, resultante de vários fatores, incluindo as variações climáticas e as atividades humanas, sendo que a degradação de terras, por sua vez, é definida pela redução/perda da fertilidade e da produtividade biológica ou econômica das terras áridas (MMA, 2006).

Entre os núcleos nacionais onde processos de desertificação podem estar ocorrendo, o núcleo da Região do Seridó (RN/PB) constitui um dos mais críticos em relação aos outros 03 núcleos (Gilbués-PI, Irauçuba-CE e Cabrobó-PE). Essa informação se dá com base em que os espaços considerados áridos no Nordeste estão inseridos na região do Seridó do Rio Grande do Norte, onde os demais núcleos foram enquadrados climaticamente como semiáridos ou subúmidos secos (MMA, 2004).

De forma isolada, o núcleo do Seridó apresenta um nível de degradação muito intenso, compreendendo uma área de aproximadamente $12 \mathrm{mil} \mathrm{km²}$, com uma população de mais de 200 mil habitantes. Esta população está dividida entre os 54 municípios da região, sendo 28 potiguares e 26 
paraibanos, o que levou a uma subclassificação realizada pelo Ministério da Integração Nacional (MMA, 2004).

Com enfoque de contribuir com a conservação dos ecossistemas frente a esse elevado processo de degradação ambiental na região do Seridó, esta pesquisa teve como objetivo principal realizar o zoneamento e a delimitação de áreas prioritárias para a conservação e/ou recuperação ambiental na Microbacia Hidrográfica do Rio Barra Nova (RN/PB). Esta microbacia representa uma importante drenagem de águas entre as microrregiões do Seridó Ocidental (RN) e do Seridó Paraibano (PB). Esta abordagem apenas foi possível através de métodos de análise e modelagem espacial junto ao Sistema de Informações Geográficas (SIG), utilizando-se de técnicas de geoprocessamento, aplicados à identificação de unidades geoecológicas (e.g. cobertura vegetal, uso do solo, relevo), as quais serviram de base fundamental para as demais etapas.

\section{METODOLOGIA}

\section{1 Área de estudo}

A Microbacia Hidrográfica do Rio Barra Nova está inserida na Bacia Hidrográfica PiancóPiranhas-Açu, englobando as microrregiões do Seridó Ocidental, Oriental e Paraibano, em uma área de aproximadamente $106.533 \mathrm{~km}^{2}$ ) (FIG 01).

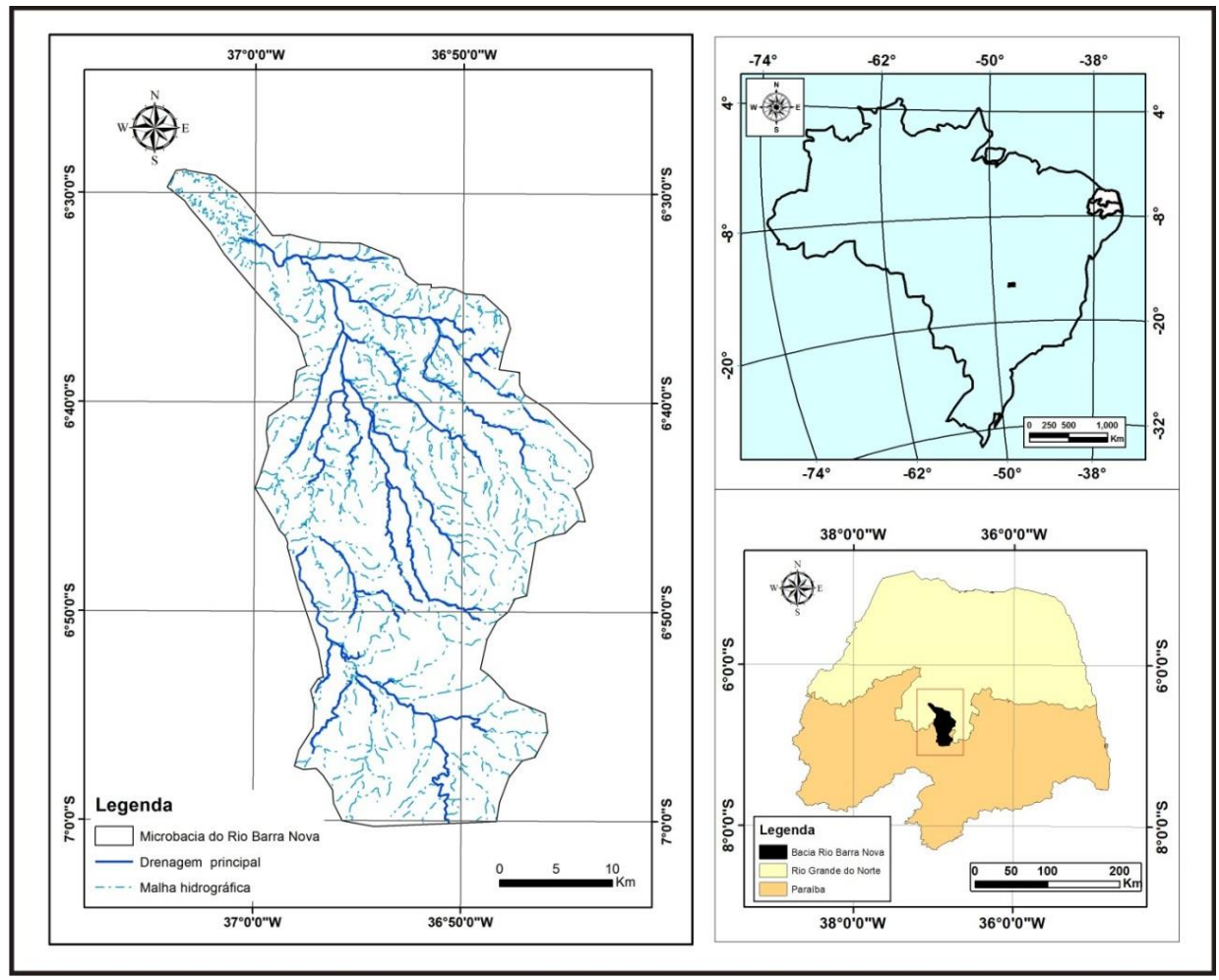

Figura 01: Mapa de localização da Microbacia do Rio Barra Nova. Fonte: Elaborado pelo autor

Segundo Alvares et al., (2013), o clima da região é o tipo Bsh (classificação de Köppen): semiárido quente, com precipitação pluviométrica média anual baixa $(<800 \mathrm{~mm})$ e uma estação 
acentuadamente seca, sendo um dos climas mais quentes e secos do Nordeste brasileiro, com temperatura média anual em torno de $27,4^{\circ} \mathrm{C}$.

\subsection{Procedimentos metodológicos}

As etapas metodológicas para o mapeamento do uso e ocupação do solo foram divididas em: 1) levantamento bibliográfico e cartográfico prévio da área estudada; 2) Aquisição e Processamento Digital de Imagens-PDI, envolvendo técnicas de realce de contraste das imagens orbitais, fusão entre as bandas multiespectrais, composições coloridas no sistema de cores RGB (Red-Green-Blue) e mosaicagem das diferentes cenas processadas. A escolha das imagens partiu do critério das mesmas não apresentarem problemas relacionados à presença de nuvens, cuja presença, dependendo da quantidade e distribuição, poderia acarretar elevado comprometimento visual das imagens analisadas para a área de estudo. Dessa forma, foram selecionadas as imagens do satélite Resource-sat 1 (sensor Liss; Órbita 337; Ponto 081) de 21 de abril de 2012. 3) classificação e quantificação de área das diferentes classes de ocupação do solo presentes na região através de mapas temáticos em escala de 1:400.000 (com base na análise espectral, tonalidades e texturas das imagens), realizadas com base nas categorias descritas pelo Manual Técnico de Uso da Terra do IBGE (2006).

Por fim, a estratégia de identificação das classes de ocupação do solo, as quais foram posteriormente subdivididas no zonenamento ambiental seguido da definição de áreas prioritárias para a intervenção/gestão seguiram os precedimentos já descritos para o semiárido (COSTA et al., 2014). (TAB 01)

Tabela 01: Tabela das categorias de zoneamento/áreas prioritárias para intervenção

\begin{tabular}{|c|c|c|c|}
\hline $\begin{array}{c}\text { Categorias } \\
\text { do } \\
\text { Zoneamento }\end{array}$ & Características & $\begin{array}{c}\text { Classes de uso } \\
\text { do solo } \\
\text { Correspondente }\end{array}$ & Prioridade \\
\hline $\begin{array}{c}\text { Zona de Uso } \\
\text { Restrito }\end{array}$ & $\begin{array}{c}\text { Zonas que apenas poderão ser ocupadas } \\
\text { para atividade de recreação e } \\
\text { educacionais, cuja edificação apenas } \\
\text { poderá ser realizada mediante } \\
\text { licenciamento ambiental. }\end{array}$ & $\begin{array}{c}\text { Caatinga densa e } \\
\text { corpo hídrico } \\
\text { (açude) }\end{array}$ & Alta \\
\hline $\begin{array}{c}\text { Zona de } \\
\text { Risco }\end{array}$ & $\begin{array}{c}\text { Zonas onde a degradação ambiental e } \\
\text { ocupação irregular acarretaram em uma } \\
\text { susceptibilidade à erosão do solo devido } \\
\text { à retirada parcial da vegetação. }\end{array}$ & Caatinga rala & Elevada \\
\hline $\begin{array}{c}\text { Zona de } \\
\text { Recuperação }\end{array}$ & $\begin{array}{c}\text { Zonas antropicamente alteradas que } \\
\text { apresentam um elevado risco de erosão } \\
\text { em função da ausência da cobertura } \\
\text { vegetal. }\end{array}$ & Solo exposto & Extrema \\
\hline
\end{tabular}

Fonte: Costa et al., 2014. 


\section{RESULTADOS E DISCUSSÃO}

\subsection{Aspectos Fisicos:}

Segue a descrição dos aspectos físicos do município da Microbacia do Rio Barra Nova, onde serão apresentadas as características: geológicas, geomorfológicas, hidrográficas e Hipsométricas da área de estudo (FIG 02).
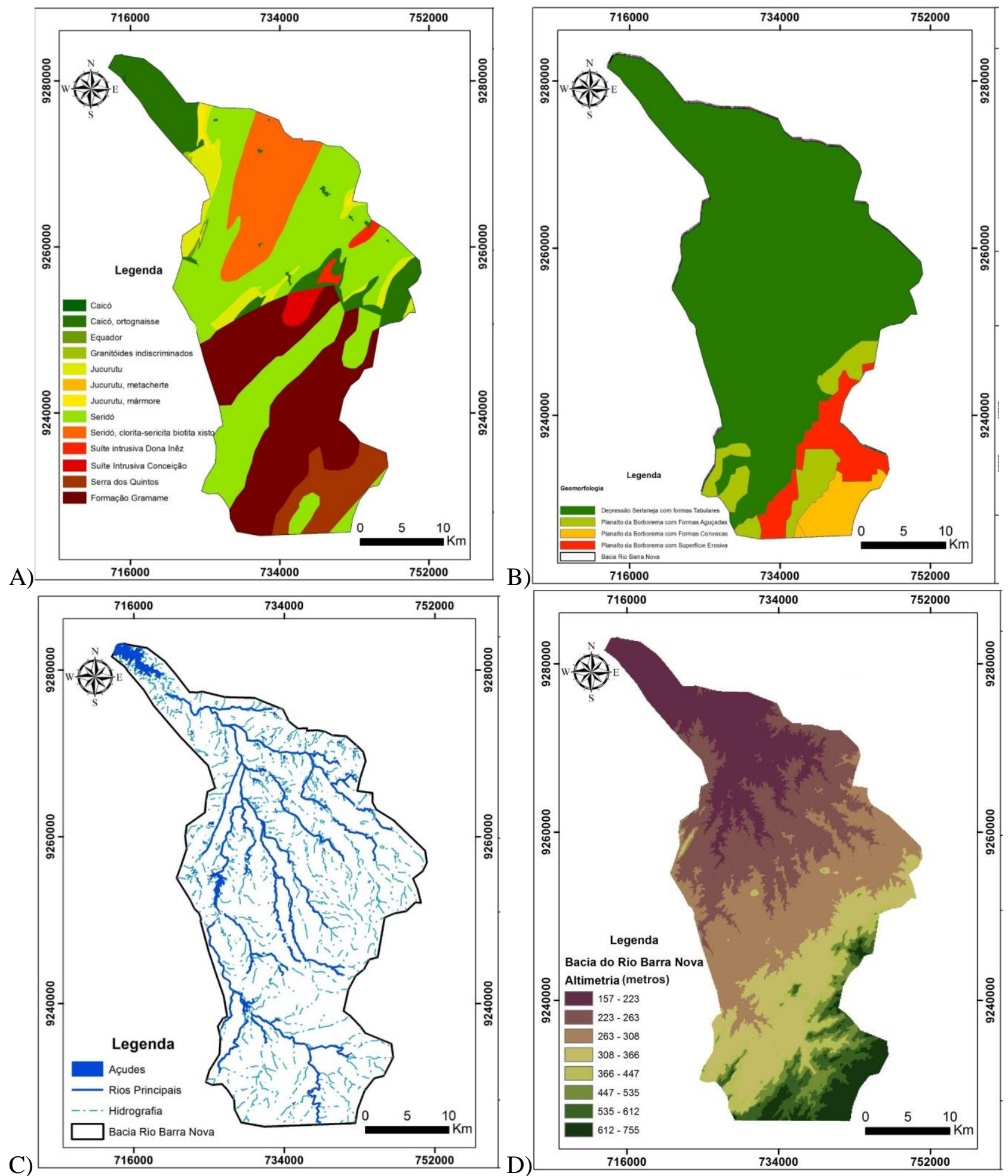

C)

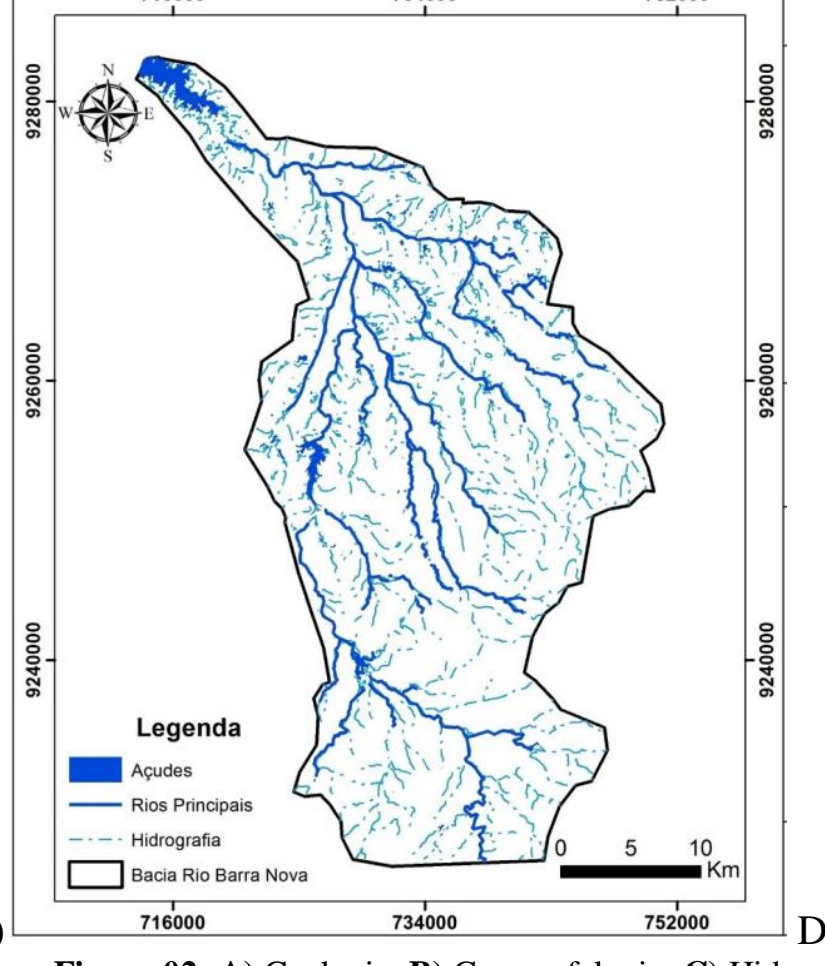

Figura 02: A) Geologia; B) Geomorfologia; C) Hidrografia; D) Hipsometria. Fonte: Elaborado pelo autor. 
A microbacia está geologiacamente inserida dentro da formação Seridó, essa estrutura geológica data do Pré-Cambriano, compreendida basicamente por rochas antigas representadas predominantemente pelas rochas ígneas ou magmáticas e as metamórficas, sendo as duas comumente denominadas de terrenos cristalinos (FELIPE.; CARVALHO, 1999). Mais também é subdividida em outras unidades geológicas como, por exemplo, a formação Gramame Jucurutu incluindo gnaisses, mármores assim como calcissilicáticas, e a Caicó composto por Anfibolito, Rocha metaultramáfica, Augen gnaisse, Metamorfica, Migmatito, Paragnaisse, Ortognaisse (CPRM, 2005).

Geomorfologicamente, a microbacia apresenta como unidades de relevo: depreseção sertaneja com formas tabulares ocupa grandes trechos da Região Nordeste e pode ser caracterizada como uma complexa depressão interplanáltica, circundando compartimentos de relevo elevado (Maciço da Borborema com formas aguçadas, convexas ou com superfície erosiva) ou se projetando a partir de bases escarpadas dos planaltos. O relevo é predominantemente plano e suave-ondulado, cortado por vales estreitos, com vertentes dissecadas e com a presença de inselbergues isolados ou em grupos, como testemunhos isolados de ciclos de erosão que atingem grande parte do sertão nordestino (MAIA.; BEZERRA, 2011) (FIG 04-B).

Em termos de hidrografia, contatou-se a presença de aproximadamente 1.400 ramificações decorrentes da microbacia do Rio Barra Nova (entre canais de $1^{\text {a }}$ a $4^{\mathrm{a}}$ ordem), que depois de calculados correspondem uma extensão de aproximadamente $1.238 \mathrm{~km}$. No tocante aos corpos hídricos, a bacia apresenta dois grandes açudes: o Açude Itans, localizado no município de Caicó RN, construído pelo Departamento Nacional de Obras Contra as Secas (DNOCS) com uma área de aproximadamente 871,2 hectares, e o Açude Esguicho, localizado no município de Ouro Branco RN, construído pela Prefeitura Municipal, com uma área de aproximadamente 321,1 hectares (FIG. 04-C).

A partir do mapeamento realizado com dados da imagem SRTM, observa-se que amplitude altimétrica da Microbacia hidrográfica do Rio Barra Nova é de aproximadamente 600 metros em relação ao nível do mar, com a menor altitude de aproximadamente 157 metros localizada na desembocadura do canal principal com a bacia microbacia do Rio Seridó ao norte, e a maior altitude (700 metros) situada na porção montante, ao sul (FIG. 04-D).

\subsection{Zoneamento geoambiental}

Diante das imagens de satelite provenientes do Sensoriamento Remoto foi elaborado um mapeamento de uso e ocupação do solo, onde a partir da análise das imagens foi delimitada a rede 
de drenagem hidrográfica e 03 classes de macrounidades de uso e ocupação do solo. Sendo elas: Caatinga densa, Caatinga rala e solo exposto (FIG 03 e TAB 02).

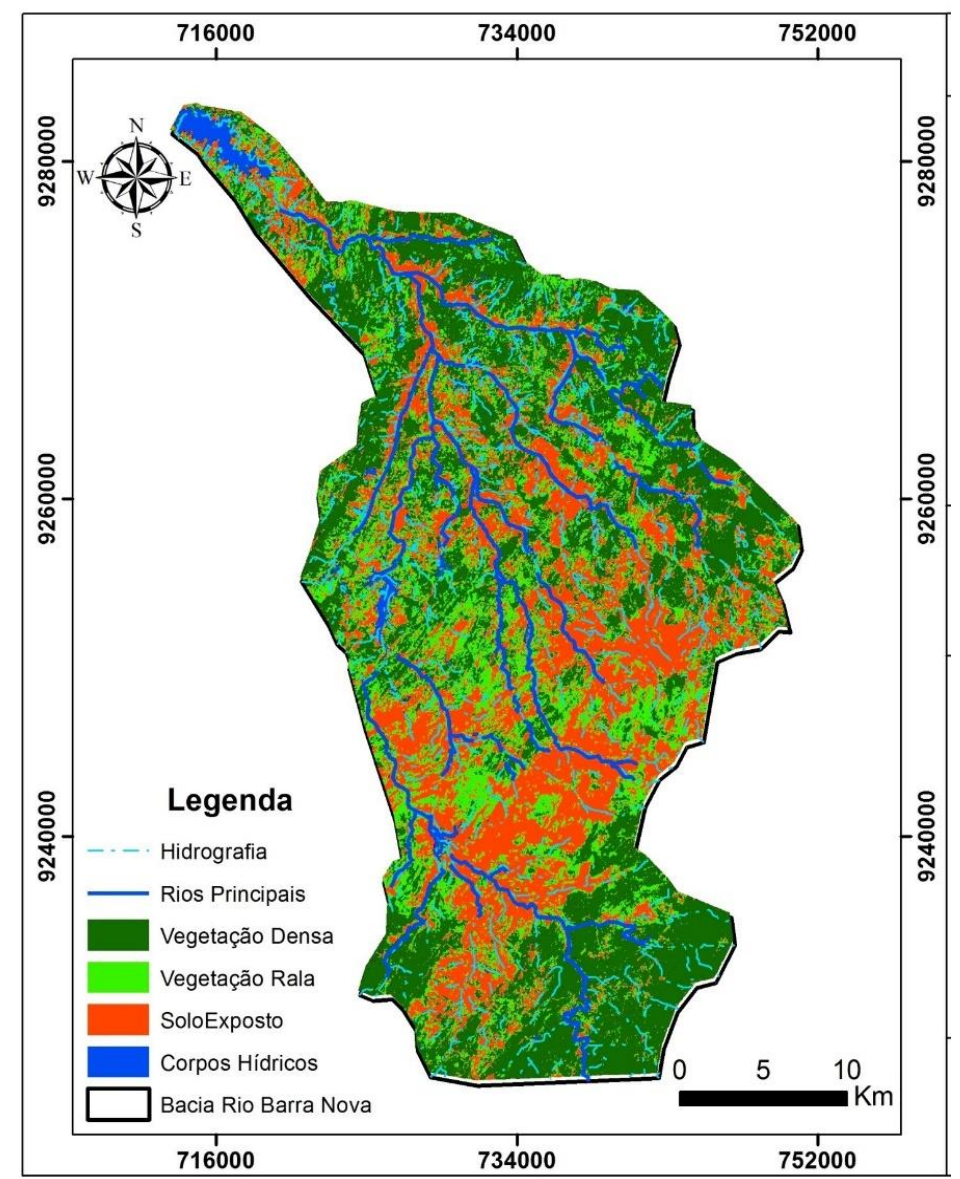

Figura 03: Mapa de cobertura da terra. Fonte: Elaborado pelo autor.

Tabela 02: Tabela das classes de uso e ocupação do solo da Microbacia do Rio Barra Nova

\begin{tabular}{c|c}
\hline CLASSES DE USO & ÁREA $\left(\mathbf{K m}^{2} / \%\right)$ \\
\hline Hidrografia & $1.238 / 1,05 \%$ \\
\hline Caatinga densa & $35.983 / 30,42 \%$ \\
\hline Caatinga rala & $44.073 / 37,25 \%$ \\
\hline Solo Exposto & $37.004 / 31,28 \%$ \\
\hline
\end{tabular}

Diante das categorias de cobertura da terra foi elaborado um zoneamento por classes de toda a área mapeada, o qual constituirá uma ferramenta auxiliar na gestão de toda a Bacia (FIG 04). 

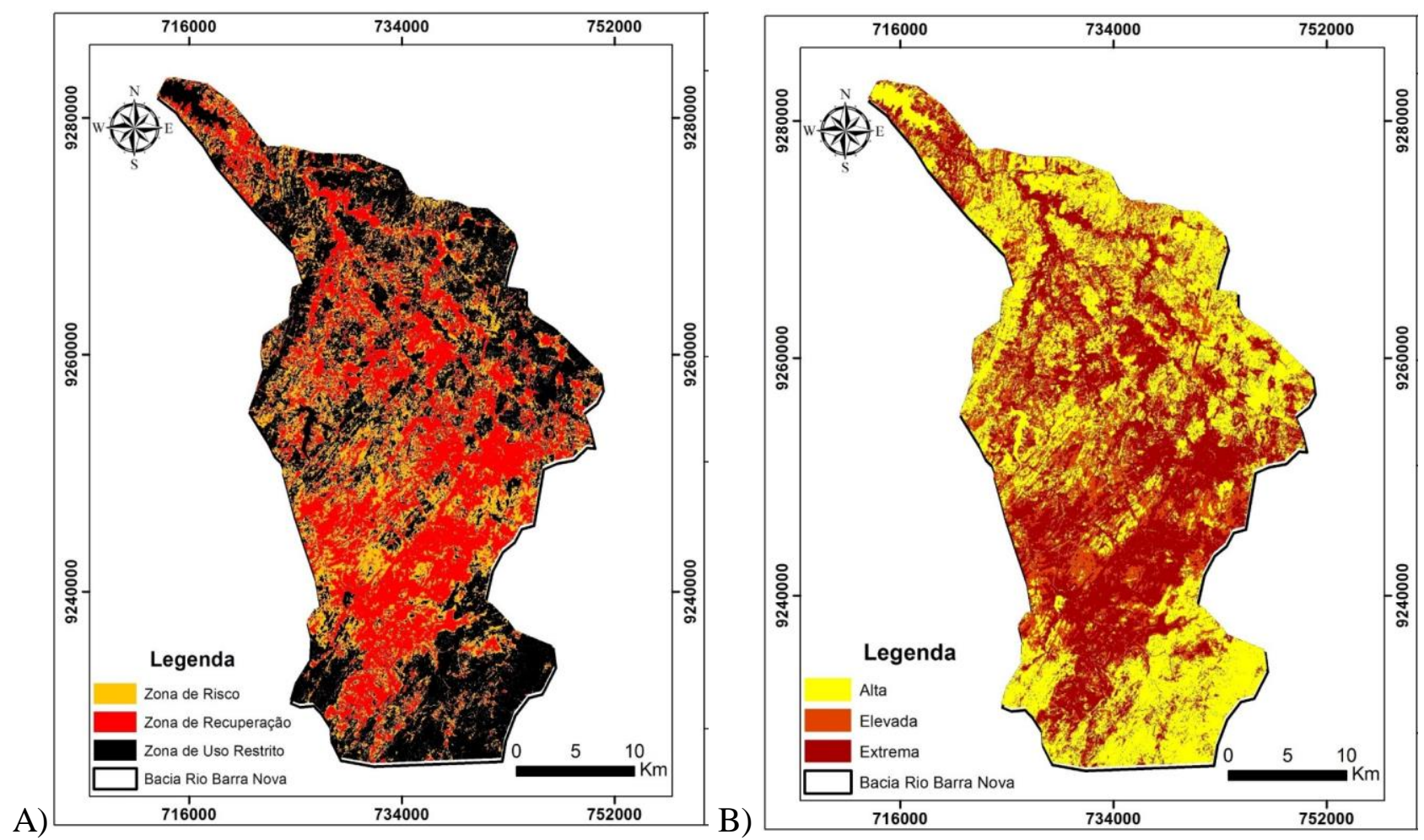

Figura 04: Mapas com o zoneamento ambiental da Microbacia do Rio Barra Nova - A) categorias de zoneamento B) Areas prioritárias para intervanção.

Essa afirmativa é feita analisando-se que apenas 30,42\% dessa área ainda apresenta uma Caatinga densa, restando 37,25\% de Caatinga rala e 31,28\% solo exposto. Portanto, vertifica-se que quase $70 \%$ da área da bacia encontra-se numa área de risco e/ou para recuperação. Estas zonas foram identificadas com o objetivo de delimitar unidades de planejamento a partir das diferentes abordagens a serem implantadas na gestão das classes de uso/ocupação do solo, observando-se as características ambientais de cada tipo de ocupação.

Nesse sentido, foram delimitadas 03 zonas chave para a gestão das margens da Bacia do Rio Barra Nova RN/PB, este zoneamento consiste em identificar e delimitar situações ambientais com diferentes características: estados de degradação, vegetação remanescente, área degradada, tipos de solo, como também a matriz vegetacional que está inserida.

As diferentes zonas também foram identificadas com o objetivo de delimitar unidades de planejamento a partir das diferentes abordagens a serem implantadas na gestão das classes de uso/ocupação do solo, observando-se as características ambientais de cada tipo de ocupação. Estas zonas foram divididas em: 1) Zona de uso restrito: Zonas que apenas poderão ser ocupadas para atividade de recreação e educacionais, cuja edificação apenas poderá ser realizada mediante licenciamento ambiental 2) Zona de risco: Zonas onde a degradação ambiental e ocupação irregular acarretaram em uma susceptibilidade à erosão do solo devido à retirada parcial da vegetação e 3) Zona para recuperação ambiental: Zonas antropicamente alteradas que apresentam um elevado risco de erosão em função da ausência da cobertura vegetal (FIG 06-A). 
Posteriormente ao zoneamento, identificou-se a diversidade de zonas apresentando áreas mais degradadas e necessitando de uma intervenção rápida, assim como zonas susceptíveis a degradação e zonas mais conservadas do ponto de vista da cobertura vegetal.

Portanto, com vistas em auxiliar na gestão das margens, foram delimitadas as áreas prioritárias para intervenção as quais direcionam a urgência das ações a serem implantadas, sendo subdivididas em 03 áreas prioritárias: Alta, Elevada e Extrema (FIG 06-B).

A extrema prioridade foi delimitada para as áreas de solo exposto, necessitando de intervenção rápida no sentido de recuperá-las, devido seu alto grau de degradação e/ou suceptibilidade à erosão do solo. Já a elevada prioridade foi enquadrada nas zonas de risco indicadas no zoneamento, que equivalem às áreas de Caatinga rala e ao próprio reservatório. Estas representam áreas susceptíveis à degradação, necessitando tanto de atividades de adensamento da vegetação, assim como de sensibilização ambiental, principalmente voltadas para evitar a retirada da vegetação, evitar a pecuária intensiva e o uso de agrotóxicos junto às margens. Por fim, as áreas de alta prioridade para intervenção equivalem às zonas de uso restrito, onde ainda existem trechos de Caatinga densa, apresentando assim, um maior potencial para conservação natural, necessitando de ações voltadas para preservação do meio ambiente, além das práticas de sensibilização ambiental já listadas para as áreas de elevada prioridade.

\section{CONCLUSÕES}

A atual conjuntura paisagística da ocupação da Microbacia do Rio Barra Nova requer uma imediata realização de ações voltadas à recuperação ambiental das áreas degradadas, assim como o adensamento da vegetação nas áreas de solo exposto. A utilização de imagens orbitais dos satélites Resource-Sat, mostrou-se uma ferramenta apta para análise espaço-temporal e detecção fatores antrópicos na área de estudo. A partir dos dados obtidos neste trabalho, concliu-se que a Bacia do Rio Barra Nova apresenta um estágio de degradadação acentuado, com uma incipiente vegetação nativa remanescente. Ainda quanto a esse aspecto da degradação, constatou-se a necessidade de intervenção rápida, a qual não possui nenhuma cobertura vegetal arbustivo-arbórea (apenas o solo exposto), devido a retirada intensa da vegetação. Portanto, a atual conjuntura paisagística da ocupação da Bacia do Rio Barra Nova RN/PB, urge a tomada imediata de ações voltadas à recuperação ambiental das áreas degradadas, assim como o adensamento da vegetação nas áreas de solo exposto.

No tocante as ações antrópicas de uso desse espaço, indicou-se como de elevada prioridade a realização de campanhas de sensibilização ambiental, principalmente voltadas para evitar a retirada da vegetação, evitar a pecuária intensiva e o uso de agrotóxicos junto às margens dos rios e açudes presentes no local de estudo. Dessa forma, concluir-se que o Geoprocessamento, mostra-se como 
uma ferramenta indispensável para o planejamento Ambiental, indicando-se uma série de áreas prioritárias, com estratégias diferenciadas para a gestão desse espaço, contribuindo para obtenção de dados como: conservação, recuperação, campanhas de educação ambiental, dentre outros métodos mitigadores.

\section{REFERÊNCIAS BIBLIOGRÁFICAS:}

AB'SÁBER, A.N. Problemática da desertificação e da savanização no Brasil intertropical. Geomorfologia, São Paulo, n. 53, p.19, 1977.

AESA - Agência Executiva de Gestão das Águas do Estado da Paraíba. Disponível em < http://www.aesa.pb.gov.br/geoprocessamento/geoportal/mapas.html> Acesso em 04 de fevereiro de 2013.

AGOSTINHO, A. A.; THOMAZ, S. M.; GOMES, L. C. Conservação da biodiversidade em águas continentais do Brasil. Megadiversidade, v. 1, n. 1, p. 70-78, 2005.

ALVARES, C. A.; STAPE, J. L.; SENTELHAS, P. C.; GONÇALVES, J. L. M.; SPAROVEK, G. Köppen's climate classification map for Brazil. Meteorologische Zeitschrift, Fast Track. 2013.

ALVES, H. M. R.; VIEIRA, T. G. C. E ANDRADE, H. "Sistemas de Informação Geográfica na avaliação de impactos ambientais provenientes de atividades agropecuárias", Revista Agropecuária e Ambiente/Informe Agropecuário. v. 21, n. 202, p. 99-109, 2000.

AMARO, V. E.; SILVA, D. R. V.; SOUZA, F. E. S.; SOUTO, M. V. S.; ARAÚJO, A. B.; SOUZA, A. S. Uso de imagens IKONOS de alta resolução como base para o mapeamento temático em escala 1:10.000 do Sistema Estuarino Apodi-Mossoró e seus entornos no Litoral Setentrional do Rio Grande do Norte. In: Anais... XII Simpósio Brasileiro de Sensoriamento Remoto, Goiânia, Brasil, 16-21 abril 2005, INPE, p. 3395-3401.

BERTRAND, G. Paisagem e Geografia Física global: esboço metodológico. Caderno de Ciências da Terra, São Paulo, v. 13, p. 1-21, 1969.

BRASIL. PROJETO RADAMBRASIL. 1981. Folhas SB. 24/25 Jaguaribe/Natal. Rio de Janeiro: Projeto RADAMBRAIL. (série Levantamento de Recursos Naturais, v. 23). p. 349-484, 1981.

- Ministério do Meio Ambiente. Articulação do Semi-Árido Brasileiro - ASA e Deutsche Gesellschaft fur Technische Zusammenarbeit - GTZ. Parceria para o Combate a Desertificação: Governo Federal, Sociedade Civil e Cooperação Alemã. Recife/PE. MMA. 2006.

Programa de Ação Nacional de Combate à Desertificação e Mitigação dos Efeitos da Seca - PAN Brasil. Brasilía. MMA. Secretaria de Recursos Hídricos. 2004

CÂMARA, G. E MEDEIROS, J. S. Geoprocessamento para projetos ambientais. São José dos Campos, INPE (Relatório do INPE). p. 39, 1996

CÂMARA, G.; SOUZA, R.C.M.; FREITAS, U.M. E GARRIDO, J. "SPRING: Integrating remote sensing and GIS by object-oriented data modelling", Computers \& Graphics, 20:(3), pp. 395-403. (may-june, 1996). 
CÂMARA, G.; MONTEIRO, A. M.; MEDEIROS, J. S. Introdução a Ciência da Geoinformação

- São José dos Campos, INPE, 2004.

CARVALHO JUNIOR, W.; CHAGAS, C. S.; PEREIRA, N. R. E STRACH, J. C. M. "Elaboração de Zoneamentos agropedoclimáticos por geoprocessamento: soja em municípios do Rio Grande do Sul", Revista Brasileira de Ciências do Solo, Viçosa, v. 27, n. 2, 2003.

CHRISTOFOLETTI, A. Modelagem de sistemas ambientais. São Paulo: Edgard Blücher LTDA, 1999.

Geomorfologia. 2a edição. São Paulo: Edgar Blücher LTDA. 1980.

COSTA, D. F. S.; GUEDES, J. C. F.; DE MEDEIROS ROCHA, R. Zoneamento geoecológico aplicado à gestão das margens de reservatórios no semiárido brasileiro - Estudo de caso no Açude Itans (Caicó-RN). Revista de Geografia da UFPE. v. 29, n. 3, 2012 (in press).

CPRM. Diagnóstico do município de Caicó. Projeto cadastro de fontes de Abastecimento por Água subterrânea do Rio Grande do Norte. Brasil, Recife/PE. 2005.

CPRM - Companhia de Pesquisa de Recursos Minerais. Disponível em <http://geobank.sa.cprm.gov.br/>. Acesso em 04 de Fevereiro de 2013.

DUARTE, S. M. A. Diagnóstico Ambiental e Planejamento da Microbacia Hidrográfica Timbaúba no Brejo Paraibano, através de Técnicas de Fotointerpretação e sistema de Informações Geográficas. Areia-PB, PPGMSA/UFPB. 2003

FARIAS FILHO, A. F. E ARAÚJO, Q. R. Zoneamento do meio físico do município de Ilhéus, Bahia, Brasil, utilizando a técnica de geoprocessamento. Boletim Técnico n. 187. Ilhéus, Bahia, CEPLAC/CEPEC. p. 20, 2003

FARIA, K. M. S.; SIQUEIRA, M. N.; CARNEIRO, G. T.; CASTRO, S. S. Análise Geoecológica da Conservação Ambiental das Sub-Baciasdo Rio Claro (GO) e do Rio Garças (MT). Revista Nordestina de Ecoturismo, Aquidabã, v.5, n.1, 2011/ 2012.

FEliPe, J. L. A.; CARVAlHO, E. A. Atlas escolar do Rio Grande do Norte. João Pessoa-PB: Grafset, p.39-54, 1999.

IBGE - (Instituto Brasileiro de Geografia e Estatística), Manual técnico de uso da Terra. 2. ed. Rio de Janeiro, 2006.

IDEC. Açudes Públicos do Rio Grande do Norte. Características Físicas e Técnicas - Fundação Instituto de Desenvolvimento do Rio Grande do Norte. Natal/RN, 1991.

IESA - Instituto de Estudos Sócio-Ambientais: Boletim Goiano de Geografia. Diagnóstico geoambiental da bacia hidrográfica semiárida do Rio Acaraú: subsídios aos estudos sobre desertificação. Goiânia/GO: IESA, 2008.

LACERDA, A. V. A semi-aridez e a gestão em Bacias Hidrográficas: visões e trilhas de um divisor de idéias. João Pessoa (Paraíba), Editora Universitária. p. 164, 2003 
LIMA, V. Avaliação das terras da sub-bacia hidrográfica do Riacho do Cunha nos municípios de Areia e Remígio, estado da Paraíba. (Dissertação de mestrado). Areia, PPGMSA/CCA/UFPB. p. $51,2003$.

MAIA, R. P.; BEZERRA, F. H. R. Neotectônica, geomorfologia e sistemas fluviais: Uma análise preliminar do contexto nordestino. Revista Brasileira de Geomorfologia - v. 12, n. 3, 2011.

MEIRELES, A. J. A., VICENTE DA SILVA, E. Abordagem geomorfológica para a realização de estudos integrados para o planejamento e gestão em ambientes flúvio-marinhos. Scripta Nova. Revista electrónica de geografía y ciencias sociales, Universidad de Barcelona, v. 06, n. 118, 2002.

MOLENAAR, M. An introduction into the theory of topologic and hierarchical object modeling in geo-information systems. Wageningen: Wageningen Agricultural University-Center for GeoInformation Processing. p. 135, 1996

NICÁCIO, J.A., LOCH, C. Elementos necessários para o planejamento de sustentabilidade dos municípios de médio e pequeno porte. Florianópolis: Departamento de Cartografia da UFSC, 2002.

NIMER, E. Climatologia do Brasil. Rio de Janeiro: IBGE, 1979.

NIMER, E. Climatologia do Brasil. 2. ed. Rio de Janeiro: IBGE, 1989.

OSTENSEN, O. Mapping the future of geomatics. Paris, Prentice Hall International: ISO/TC 211 (Bulletin, 1). p. 49, 1995

PEDRA, C. S.; CATELANI, C. S.; RESENDE, S. R. S. E BATISTA, G. T. "Levantamento do meio físico de uma microbacia no município de Natividade da Serra, SP, através de técnicas de geoprocessamento e sensoriamento remoto, para suporte ao Programa Estadual de Microbacias Hidrográficas (PEMBH)", Anais... XII Simpósio Brasileiro de Sensoriamento Remoto, Goiânia, Brasil. , INPE, p. 3887-3889. (16-21 abril 2005).

PINTO, L. V. A.; FERREIRA, E.; BOTELHO, S. A. E DAVIDE, A. C. "Caracterização física da bacia hidrográfica do Ribeirão Santa Cruz, Lavras, MG e uso conflitante da terra em suas áreas de preservação permanente", Cerne. Universidade Federal de Lavras, v. 11, n. 1, p. 49-60, 2005

ROCHA, J. S. M. da: Manual de Projetos Ambientais. Santa Maria, Imprensa Universitária/UFSM. 1997.

ROCHA, J. V. "El Sistema de Informaciones Geográficas (SIG) en los contextos de planificación del medio físico y de las cuencas hidrográficas", II Curso Internacional de Aspectos Geológicos de Protección Ambiental (Capítulo 9, pp. 102-113). 2005

ROCHA, O. et al. A bacia hidrográfica como unidade de estudo e planejamento. In: Espíndola et al. (Orgs.). A bacia hidrográfica do Rio Monjolinho: uma abordagem ecossistêmica e a visão interdisciplinar. São Carlos: RIMA, 2000.

SANTOS, R. F. Planejamento Ambiental: teoria e prática. São Paulo: Oficina de Texto, 2004. 
SCHÄFER, A.; PEREIRA, R.; AGRA, G. "Uso do Sensoriamento Remoto e Sistema de Informação Geográfica (SIG) no monitoramento da polícia ambiental do Rio Grande do Sul: Curso de Capacitação", 4 ${ }^{a}$ Jornada de Educação em Sensoriamento Remoto no Âmbito do Mercosul. São Leopoldo, RS (11 a 13 de agosto de 2004).

SCHIAVETTI, A; CAMARGO, A.F.M (Eds.). Conceitos de bacias hidrográficas: teorias e aplicações. Ilhéus: Editus, 2002.

SILVA, A. B.; BRITES, R. S. E SOUSA, A. R. "Caracterização do meio físico da microbacia Quatro Bocas, em Angelim, PE, e sua quantificação por Sistema de Informação Geográfica”, Pesq. Agropec. Bras. v. 34, n. 1, p. 109-117, 1999),

SILVA DE FARIA, K. M.; SIQUEIRA, M. N.; CARNEIRO, G. T.; CASTRO, S. S. Análise geoecológica da conservação ambiental das sub-bacias do Rio Claro (GO) e do Rio Garças (MT). Anais... do I Seminário Nacional de Geocologia e Planejamento Territorial IV Seminário do Geoplan. Universidade Federal de Sergipe. 11 a 13 de Abril de 2012.

SPÖRL, C.; ROSS, J. L. S. Análise comparativa de fragilidade ambiental com aplicação de três modelos. GeoUSP - Espaço e Tempo, São Paulo, USP, n. 15, p. 39-49, 2004.

TRANCOSO, R.; CARNEIRO FILHO, A.; FERREIRA, D. A. C. E NOGUERA, S. P. "Sistemas de Informação Geográfica como ferramenta para o diagnóstico e gestão de macrobacias no arco do desmatamento na Amazônia", Anais... XII Simpósio Brasileiro de Sensoriamento Remoto, Goiânia, Brasil (16-21 abril 2005), INPE, p. 2405-2412.

VILA-SILVA, J. S. Análise multivariada em zoneamento para planejamento ambiental. Estudo de caso: bacia hidrográfica do alto rio Taquari MS/MT. Tese. Universidade de Campinas. Campinas. 2003.

\section{AGRADECIMENTOS:}

Ao Laboratório de Monitoramento Ambiental - LAMA (UFRN/CERES - Campus de Caicó), pelo apoio logístico e instrumental no âmbito do projeto "Dinâmica multitemporal da disponibilidade hídrica dos reservatórios do município de Caicó-RN" (UFRN/PROPESQ PVF98192013).

Recebido em: 14/08/2016

Aceito para publicação em: 01/10/2016 